\title{
Determinants of intensive care prognosis in patients with "platelet indices" in chronic obstructive pulmonary disease and lung cancer
}

\author{
๑G Güler Eraslan Doğanay, @Mustafa Özgür Cırık \\ University of Health Sciences, Atatürk Chest Diseases and Thoracic Surgery Training and Research Hospital, Department of Anesthesiology \\ and Reanimation, Ankara, Turkey
}

Cite this article as: Eraslan Doğanay G, Cırık MÖ. Determinants of intensive care prognosis in patients with "platelet indices" in chronic obstructive pulmonary disease and lung cancer. J Health Sci Med 2021; 4(3): 329-333.

\begin{abstract}
Aim: Platelet activation and consumption indicate worse prognosis in critical ill patients. Researchers found that the lungs play an important role in the production of mature platelets. Chronic obstructive pulmonary disease (COPD) is a respiratory disease affects the lungs and also has systemic effects due to inflammation. This study was conducted to examine prognosis and mortality with Platelet indices in COPD and lung cancer patients in intensive care.

Material and Method: We extracted clinical data including patient demographics, Charlson Comorbidite Index, Acute Physiology and Chronic Health Evaluation II, Sequential Organ Failure Assessment scores, length of stay in ICU, length of stay in hospital, duration of mechanical ventilation, inotrope use, Plt count, MPV, PDW, and PCT values and 30-day mortality retrospectively.

Results: This study was conducted with the 344 COPD and 84 lung cancer patients' data analysis admitted to ICU. In this study we found that Plt count, PDW, and MPV are also predict COPD while Plt count and MPV predict lung cancer. The study shown that, CCI, APACHE II, SOFA score, intrope use, MV duration and mortality were higher in lung cancer patients compared to COPD patients.

Conclusion: Plt indices can be a determinant in patients with COPD and lung cancer but they might not make a clear distinction for prognosis.
\end{abstract}

Keywords: Platelet indices, chronic obstructive pulmonary disease, lung cancer, platelet count, MPV, intensive care

\section{INTRODUCTION}

Chronic obstructive pulmonary disease (COPD) is a respiratory disease affects the lungs and also has systemic effects due to inflammation.

It has recently been found that the lungs play an important role in the production of mature platelets (1). High Plt count in a diversity of malignant diseases is connected with mortality. Additionally, mean platelet volume (MPV) is a valuable indicator in betimes diagnosis and prognosis of lung cancer. Irregularity in produce of platelet may be related to carcinogenesis $(2,3)$.

Platelets (Plts) are blood cells that initiate hemostasis through thrombosis with coagulation factors in physiological and pathological processes and maintain the vascular endothelial cell integrity (4). Plt count, plateletcrit (PCT), MPV, platelet distribution width (PDW) are called Plt indices and signed of Plt size, Plt morphology, and proliferation (5).
MPV (PCT/PLT count) measures the volume of the circulating Plts. It is known that MPV is associated with acute exacerbation of COPD patients (6). PDW measures the volume of Plt distrubution. PCT (Plt x MPV / $10.000)$ is the parameter that defines the blood volume contained by Plts. PCT has been related to COPD and cardiovascular diseases (7).

Plt activation and destruction indicate worse prognosis in critical ill patients (8). Occurring thrombocytopenia in Intensive Care Unit (ICU) patients might be the result of hemodilution, destruction, consumption, and sequestration of Plts (9-11). Some studies evaluated Plt indices relation with sepsis severity and prognosis in ICU (12-14).

This study was conducted to examine prognosis and mortality with Plt indices in COPD and lung cancer patients in ICU. 


\section{MATERIAL AND METHOD}

After ethical committee approval from the Medical Specialization Training Board of Atatürk Chest Diseases and Thoracic Surgery Training and Research Hospital (Date: 17/12/2020, Decision No: 705), ICU admissions between January 1, 2018 and December 31, 2019 were screened retrospectively. This study was carried out in accordance with the principles of the Declaration of Helsinki

We extracted clinical datas including patient demographics, Charlson Comorbidite Index (CCI), Acute Physiology and Chronic Health Evaluation II (APACHE II), Sequential Organ Failure Assessment (SOFA) scores, length of stay in ICU (LOS ICU), length of stay in hospital(LOS H), duration of mechanical ventilation(MV), inotrope use, Plt count, MPV, PDW, and PCT values. Data on patient deaths (30-day mortality) has been obtained from the Death Notification System.

Inclusion criteria;

- Patients over the age of 18 who applied to intensive care between 1st January, 2018 and 31th December, 2019

- LOS ICU was more than $24 \mathrm{~h}$

Exclusion criteria;

- Included age $<18$ years

- Patients with active hemorrhage or hematological diseases

- Patients with missing datas

- Patients who had used anti-Plt drugs (clopidogrel)

- Patients with disease other than COPD and Lung Cancer

- Patients who received chemotherapy (CT) and/or radiotherapy(RT) (Figure 1).

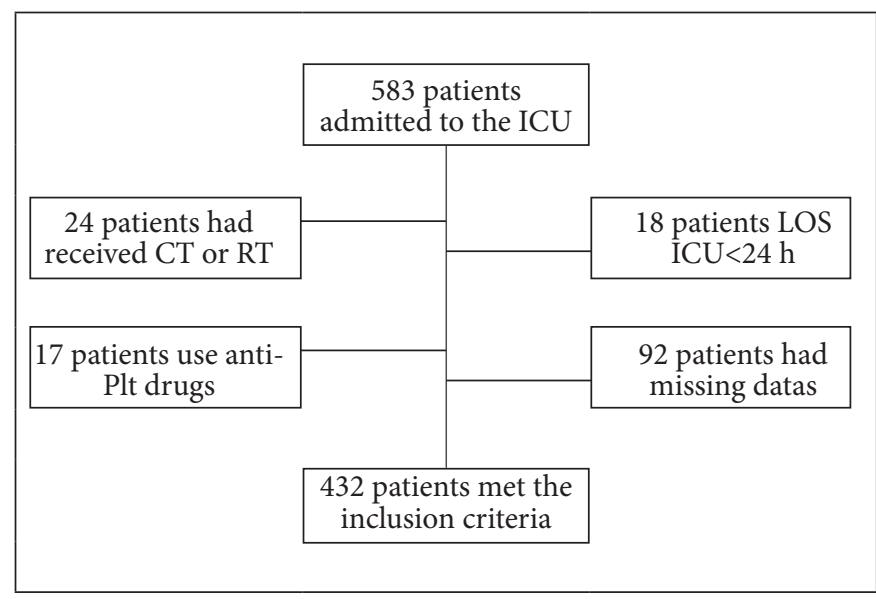

Figure 1. Flow chart of patients

\section{Statistical Methods}

The results were compared using Statistical Package for the Social Sciences, version 22.0 (SPSS Inc., Chicago, IL, United States). Whether the distribution of continuous variables were normal or not was determined by Kolmogorov Smirnov test. Continuous data were described as mean $\pm \mathrm{SD}$ and median (interquartile range) for skewed distributions. Categorical data presented as number and percentage.

Statistical analysis differences in not normally distributed variables between two independent groups were compared. Categorical variables were compared using Pearson's chi-square test or fisher's exact test.

First of all it was used one variable multinominal logistic regression with risk factors that is thought to be related with COPD and Lung Cancer. Risk factors that has $\mathrm{p}$ -value $<0.25$ one variable logistic regression was included to model on multivariable logistic regression. ROC curve analysis was used to determine the cut off points. It was accepted $\mathrm{p}$-value $<0.05$ as significant and $0.05<\mathrm{p}$ -value $<0.10$ borderline significant level on all statistical analysis.

\section{RESULTS}

This study was conducted with the 344 COPD and 88 lung cancer patients' data analysis admitted to ICU. In this study, 279 (64.6\%) males and 153(35.4\%) females included, and the mean age of patients was $70.92 \pm 11.11$ years.

When COPD and lung cancer patients were compared, the ages of lung cancer patients were statistically lower than COPD patients. The rate of male patients, APACHE II score, CCI, SOFA, intrope use, MV duration and mortality were statistically significantly higher in lung cancer patients compared to COPD patients (Table 1).

In order to determine the factors predicting COPD, logistic regression analysis was applied for univariate and Backward wald method was used for multivariate. According to the results of the 4th step (the last step of the analysis), it was understood that age, APACHE II, SOFA, Plt count, PDW and MPV predict COPD. Increase in age, APACHE II, Plt count, PDW and MPV, increases the risk of COPD but SOFA scores are lower in COPD patients (Table 2). Similarly according to The results for lung cancer; age, gender, APACHE II, CCI score, Plt count and MPV predicted lung cancer (gender and MPV borderline significant $0.05<\mathrm{p}<0.10$ ). Decrease in age, increase in APACHE II, SOFA, CCI score, Plt count and MPV increases the risk of lung cancer. In addition, the lung cancer risk is higher in men than in women (Table 3 ). 


\begin{tabular}{|c|c|c|c|c|c|c|c|}
\hline $\mathrm{n}: 428$ & \multicolumn{3}{|c|}{ COPD (n:344) } & \multicolumn{3}{|c|}{ Lung cancer (n:84) } & $\mathbf{p}$ \\
\hline \multicolumn{8}{|l|}{ Gender. n (\%) } \\
\hline Male & \multicolumn{3}{|c|}{$215(62.5 \%)$} & \multicolumn{3}{|c|}{$64(76.2 \%)$} & 0.018 \\
\hline Female & \multicolumn{3}{|c|}{$129(37.5 \%)$} & \multicolumn{3}{|c|}{$24(23.8 \%)$} & \\
\hline Age & 72.14 & \pm 11.57 & $72(18)$ & 67.42 & \pm 10.33 & $67(15)$ & 0.001 \\
\hline Mortality & \multicolumn{3}{|c|}{$115(33.4 \%)$} & \multicolumn{3}{|c|}{$54(64.3 \%)$} & $<0.001$ \\
\hline Inotrop use, $\mathrm{n}(\%)$ & \multicolumn{3}{|c|}{$76(22.1 \%)$} & \multicolumn{3}{|c|}{$31(36.9 \%)$} & 0.005 \\
\hline MV duration & 2.33 & \pm 5.41 & $0(2)$ & 4.10 & \pm 7.49 & $1(4)$ & $<0.001$ \\
\hline LOS ICU & 5.23 & \pm 6.03 & $3(4)$ & 5.98 & \pm 7.06 & $3(4)$ & 0.414 \\
\hline LOS H & 18.71 & \pm 14.96 & $15(14)$ & 17.36 & \pm 13.00 & $14(17)$ & 0.407 \\
\hline APACHE II & 21.88 & \pm 7.08 & $20(9)$ & 25.90 & \pm 8.19 & $26(14)$ & $<0.001$ \\
\hline CCI & 6.16 & \pm 2.10 & $6(2)$ & 8.44 & \pm 3.48 & $8(5)$ & $<0.001$ \\
\hline SOFA & 5.61 & \pm 2.29 & $5(2)$ & 6.93 & \pm 3.04 & $7(4)$ & $<0.001$ \\
\hline Plt count & 244.31 & \pm 96.36 & $227.5(118)$ & 258.59 & \pm 150.98 & $222(172)$ & 0.952 \\
\hline PDW & 17.28 & \pm 1.96 & $16.7(2.17)$ & 17.55 & \pm 1.66 & $16.9(2.25)$ & 0.127 \\
\hline PCT & 0.21 & \pm 0.08 & $0.2(0.10)$ & 0.20 & \pm 0.11 & $0.2(0.13)$ & 0.142 \\
\hline MPV & 9.01 & \pm 1.47 & $8.8(1.90)$ & 9.27 & \pm 1.76 & $9.4(2.38)$ & 0.171 \\
\hline
\end{tabular}

Table 2. Logistic regression analysis of COPD

\begin{tabular}{|c|c|c|c|c|c|c|c|c|c|c|}
\hline \multirow[t]{3}{*}{ COPD } & \multicolumn{5}{|c|}{ Univariate analyze } & \multicolumn{5}{|c|}{ Multivariate analyze (backward wald 4. step) } \\
\hline & \multirow[t]{2}{*}{ Wald } & \multirow{2}{*}{$\mathbf{p}$} & \multirow[t]{2}{*}{ OR } & \multicolumn{2}{|c|}{ 95\% CI for $\operatorname{EXP}(B)$} & \multirow{2}{*}{ Wald } & \multirow[t]{2}{*}{$\mathbf{p}$} & \multirow{2}{*}{ OR } & \multicolumn{2}{|c|}{ 95\% CI for $\operatorname{EXP}(B)$} \\
\hline & & & & Lower & Upper & & & & Lower & Upper \\
\hline Age & 4.134 & 0.042 & 1.013 & 1.000 & 1.026 & 4.945 & 0.026 & 1.015 & 1.002 & 1.029 \\
\hline Gender (reference, female) & 0.157 & 0.692 & 0.932 & 0.657 & 1.321 & & & & & \\
\hline LOS hospital & 0.238 & 0.626 & 1.003 & 0.991 & 1.015 & & & & & \\
\hline LOS ICU & 1.591 & 0.207 & 0.983 & 0.958 & 1.009 & & & & & \\
\hline MV duration & 3.987 & 0.046 & 0.971 & 0.943 & 0.999 & & & & & \\
\hline APACHE II & 4.502 & 0.034 & 1.027 & 1.002 & 1.052 & 10.034 & 0.002 & 1.048 & 1.018 & 1.079 \\
\hline CCI & 6.100 & 0.014 & 1.090 & 1.018 & 1.166 & & & & & \\
\hline SOFA & 11.341 & 0.001 & 0.889 & 0.831 & 0.952 & 18.147 & $<0.001$ & 0.829 & 0.760 & 0.903 \\
\hline Plt count & 8.756 & 0.003 & 1.003 & 1.001 & 1.004 & 5.045 & 0.025 & 1.002 & 1.000 & 1.004 \\
\hline PDW & 6.616 & 0.010 & 1.148 & 1.033 & 1.276 & 6.663 & 0.010 & 1.163 & 1.037 & 1.305 \\
\hline PCT & 0.003 & 0.954 & 0.944 & 0.133 & 6.682 & & & & & \\
\hline MPV & 8.006 & 0.005 & 1.167 & 1.049 & 1.300 & 9.039 & 0.003 & 1.196 & 1.064 & 1.344 \\
\hline
\end{tabular}

\begin{tabular}{|c|c|c|c|c|c|c|c|c|c|c|}
\hline \multirow[t]{3}{*}{ Lung Cancer } & \multicolumn{5}{|c|}{ Univariate analyze } & \multicolumn{5}{|c|}{ Multivariate analyze (backward wald 4. step) } \\
\hline & \multirow[t]{2}{*}{ Wald } & \multirow[t]{2}{*}{$\mathbf{p}$} & \multirow[t]{2}{*}{ OR } & \multicolumn{2}{|c|}{$95 \% \mathrm{CI}$ for $\operatorname{EXP}(\mathrm{B})$} & \multirow[t]{2}{*}{ Wald } & \multirow[t]{2}{*}{$\mathbf{p}$} & \multirow[t]{2}{*}{ OR } & \multicolumn{2}{|c|}{ 95\% CI for $\operatorname{EXP}(B)$} \\
\hline & & & & Lower & Upper & & & & Lower & Upper \\
\hline Age & 7.636 & 0.006 & 0.977 & 0.962 & 0.993 & 16.428 & $<0.001$ & 0.955 & 0.933 & 0.976 \\
\hline Gender (reference, female) & 8.304 & 0.004 & 2.194 & 1.286 & 3.743 & 3.591 & 0.058 & 0.549 & 0.295 & 1.021 \\
\hline LOS H & 0.565 & 0.452 & 0.994 & 0.977 & 1.011 & & & & & \\
\hline LOS ICU & 0.524 & 0.469 & 1.013 & 0.979 & 1.047 & & & & & \\
\hline MV duration & 5.063 & 0.024 & 1.018 & 1.005 & 1.072 & & & & & \\
\hline APACHE II & 34.369 & $<0.001$ & 1.095 & 1.062 & 1.128 & 13.989 & $<0.001$ & 1.070 & 1.033 & 1.109 \\
\hline CCI & 63.390 & $<0.001$ & 1.465 & 1.334 & 1.610 & 48.502 & $<0.001$ & 1.458 & 1.311 & 1.622 \\
\hline SOFA & 15.466 & $<0.001$ & 1.179 & 1.086 & 1.279 & & & & & \\
\hline Plt count & 5.312 & 0.021 & 1.002 & 1.000 & 1.004 & 3.904 & 0.048 & 1.002 & 1.000 & 1.005 \\
\hline PDW & 5.949 & 0.015 & 1.177 & 1.033 & 1.342 & & & & & \\
\hline РCT & 1.555 & 0.283 & 0.220 & 0.014 & 3.480 & & & & & \\
\hline MPV & 6.304 & 0.012 & 1.199 & 1.041 & 1.382 & 3.478 & 0.062 & 1.179 & 0.992 & 1.401 \\
\hline
\end{tabular}

In order to provide the success of Plt count, PDW, PCT and MPV in predicting COPD and the cut off value, ROC curve analysis was applied. It shows that Plt, PDW, and MPV can differentiate in determining the risk of mortality in cases, that is, they can classify the patients correctly at $60.6 \%, 55.1 \%, 55.5 \%$ (moderate level) respectively. To answer the question of which value should be taken as the cut off value for this test, each sensitivity and specificity values given as a result of the analysis were examined and the optimum point was chosen. For Plt, the sensitivity value was $60.6 \%$, the specificity value was $58.6 \%$, while the cut-off value was 208.5. The sensitivity value for PDW was $37 \%$ and the specificity value was $78.6 \%$, while the cut off value was 17.45. For MPV, the sensitivity value was $71.5 \%$ and the specificity value was $40.9 \%$, while the cut off value was 8.15 (Figure 2) (Table 4). 


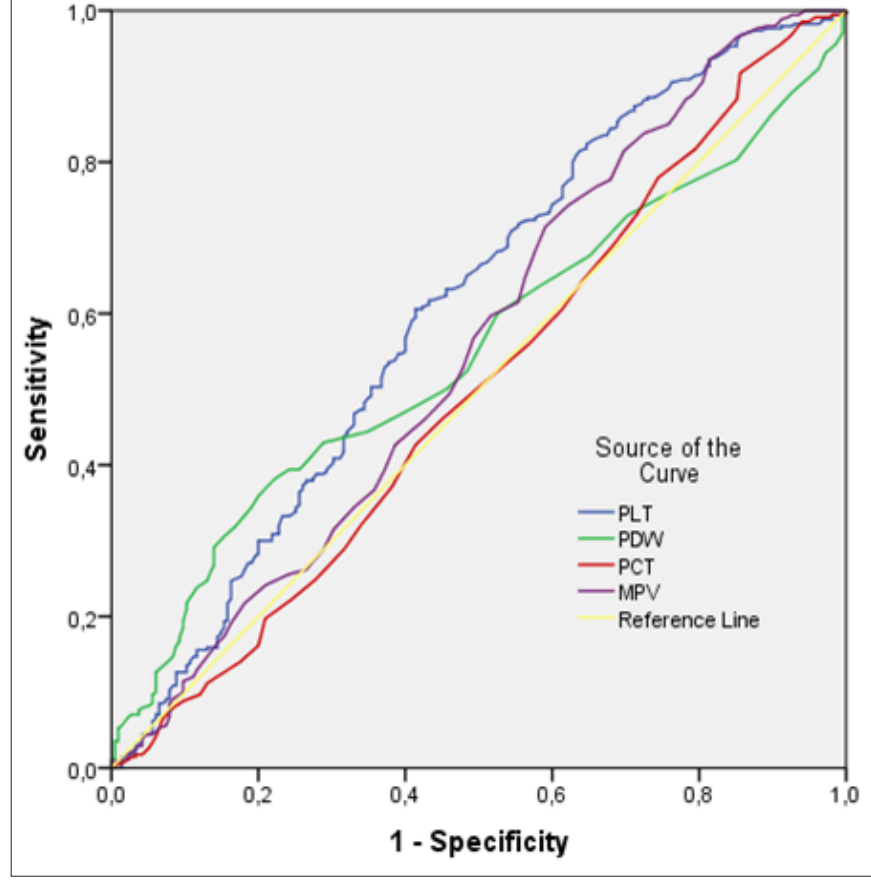

Figure 2. ROC curve analysis of COPD

\begin{tabular}{|lccccccc|}
\hline Table 4. ROC curve analysis for COPD \\
\begin{tabular}{|lccccccc|}
\hline Variable & AUC & p & $\mathbf{9 5 \%}$ CI & cutoff & Sensitivity \% & Specificity \% \\
\hline PLT & 0.606 & $<0.001$ & 0.557 & -0.655 & 208.5 & $60.6 \%$ & $58.6 \%$ \\
PDW & 0.551 & 0.042 & 0.503 & -0.599 & 17.45 & $37 \%$ & $78.6 \%$ \\
PCT & 0.502 & 0.929 & 0.452 & -0.552 & & - & \\
MPV & 0.555 & 0.030 & 0.504 & -0.605 & 8.15 & $71.5 \%$ & $40.9 \%$ \\
\hline ROC: Receiver operating curve; AUC: Area under the ROC curve & & \\
\hline
\end{tabular}
\end{tabular}

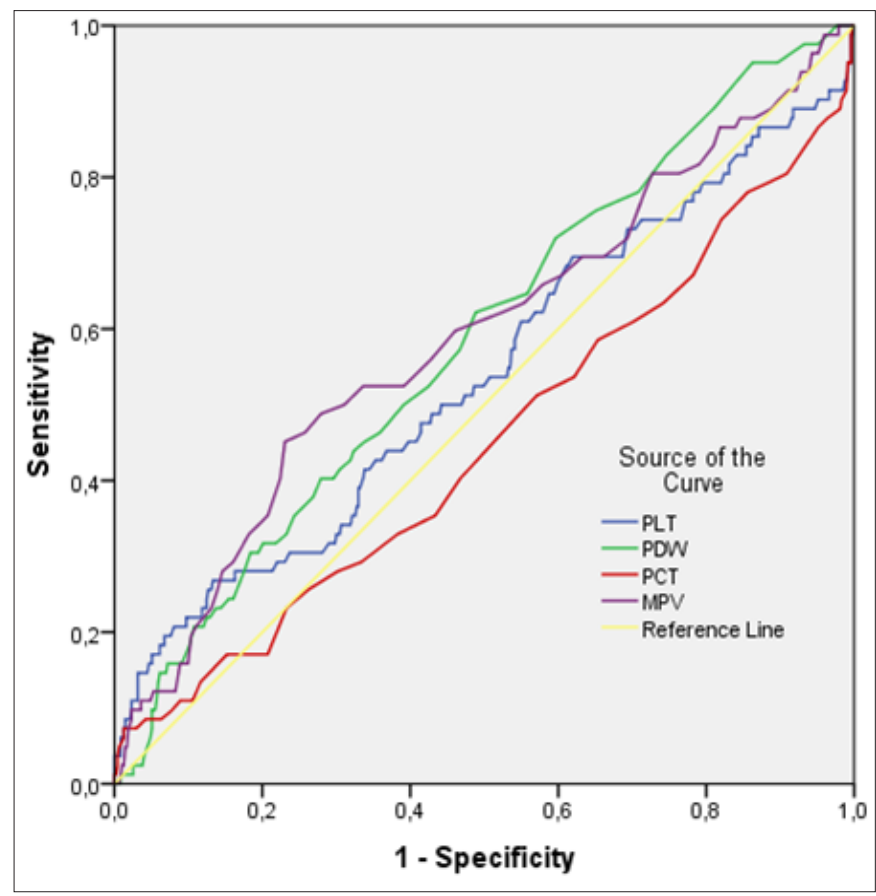

Figure 3. ROC curve analysis of lung cancer

\begin{tabular}{|lccccccc|}
\hline Table 5. ROC curve analysis of lung cancer & & \\
\hline Variable & AUC & p & 95\% CI & Cut off & Sensitivity \% & Specificity \% \\
\hline PLT & 0.538 & 0.272 & $0.464-$ & 0.612 & - & & \\
PDW & 0.586 & 0.013 & $0.520-$ & 0.652 & 16.55 & $62.2 \%$ & $51.2 \%$ \\
PCT & 0.450 & 0.147 & $0.377-$ & 0.523 & & & \\
MPV & 0.588 & 0.010 & $0.517-$ & 0.660 & 9.75 & $45.1 \%$ & $77 \%$ \\
\hline \multicolumn{7}{|l|}{ ROC: Receiver operating curve; AUC: Area under the ROC curve } & \\
\hline
\end{tabular}

In order to determine the power of PLT, PDW, PCT and MPV to differentiate malignant cases and to give a cut off value, roc curve analysis was applied. It shows that PDW and MPV can differentiate the cases, that is, they can classify the patients correctly in $58.6 \%$ and $58.8 \%$ (moderate level), respectively. To answer the question of which value should be taken as the cut off value for this test, each sensitivity and specificity values given as a result of the analysis were examined and the optimum point was chosen. For PDW, the sensitivity value was $62.2 \%$ and the specificity value was $51.2 \%$, while the cut off value was 16.55. While the sensitivity value for MPV was $45.1 \%$ and the specificity value was $77 \%$, the cut-off value was 9.75 (Figure 3) (Table 5).

\section{DISCUSSION}

There are three findings in the study that;

- Plt count, PDW, and MPV are also predict COPD while Plt count and MPV predict lung cancer.

- The ages of lung cancer patients were lower than COPD patients and the lung cancer risk is higher in men than in women. This may be due to the majority of male patients in the ICU that we studied.

- The third finding is, CCI, APACHE II, SOFA score, intrope use, MV duration and mortality were higher in lung cancer patients compared to COPD patients.

There are some studies in literature about ICU patients have shown that activation of the coagulation system, with severe infection, trauma, systemic inflammation and thrombosis might all result in changes in Plt indices $(15,16)$.

In a study they study on acute exacerbation of COPD; they found that MPV was higher in patients with exacerbation to stable disease (6). In our study age, increase in APACHE II, Plt count, MPV and PDW increases the risk of COPD similarly increase in APACHE II, Plt count and MPV increases the risk of lung cancer.

The relation between Plt indices and mortality contraversial. In a study by Zhang et al. (13) Plt and PCT were lower but MPV and PDW were higher in death patients. And similarly an other study have shown that Plt and PCT were lower, MPV and PDW were higher in death patients (17). Differently, Sezgi et al. (18) suggested that PCT and MPV levels were not different in the survived and dead groups in admission but in death group thrombocytopenia was higher in admission. In an other study, Patients with decreased platelet counts and increased MPVs at 24 hours had the highest mortality rates of all patient groups (8). And Becchi, et al. (14) evaluated the impact of MPV and platelet count, low MPV levels were associated with increased mortality. 
Zhang et al. (13) found that all Plt indices independent risk factors for mortality and patients with reduced PLT and PCT or increased MPV and PDW had shortener length of survival compared to with normal.

\section{CONCLUSION}

Although Plt indices can be a determinant in patients with COPD and lung cancer, they might not make a clear distinction for prognosis.

\section{ETHICAL DECLARATIONS}

Ethics Committee Approval: The study was carried out with the permission of Medical Specialization Training Board of Atatürk Chest Diseases and Thoracic Surgery Training and Research Hospital (Date: 17/12/2020, Decision No: 705).

Informed Consent: Because the study was designed retrospectively, no written informed consent form was obtained from patients.

Referee Evaluation Process: Externally peer-reviewed.

Conflict of Interest Statement: The authors have no conflicts of interest to declare.

Financial Disclosure: The authors declared that this study has received no financial support.

Author Contributions: All of the authors declare that they have all participated in the design, execution, and analysis of the paper, and that they have approved the final version.

\section{REFERENCES}

1. Lefrancais E, Ortiz Munoz G, Caudrillier A, et al. The lung is a site of platelet biogenesis and a reservoir for haematopoietic progenitors. Nature 2017; 544: 105-9.

2. Nikolic I, Kukulj S, Samarzija M, et al. Neutrophil-to-lymphocyte and platelet-to-lymphocyte ratio help identify patients with lung cancer, but do not differentiate between lung cancer subtypes. Croat Med J 2016; 57: 287-92.

3. Omar M, Tanriverdi O, Cokmert S, et al. Role of increased mean platelet volume (MPV) and decreased MPV/platelet count ratio as poor prognostic factors in lung cancer. Clin Respir J 2018; 12: 922-9.

4. Golebiewska EM, Poole AW. Platelet secretion: from hemostasis to wound healing and beyond. Blood Rev 2015; 29: 153-62.

5. Hoffbrand AV, Moss PAH, Pettit JE. Essential Hematology. Blackwell Publishing, Malden MA 2006; 5: 106-10.

6. Ozsarı E, Kocak MZ. Clinical significance of mean platelet volume/lymphocyte ratio and mean platelet volume/platelet ratio in the exacerbation of chronic obstructive pulmonary disease. Eur Res J 2019; 5: 6. 1001-6.

7. Kalemci S, Akin F, Sarihan A, Sahin C, Zeybek A, Yilmaz N. Relationship between hematological parameters and severity of chronic obstructive pulmonary disease. Pol Arch Intern Med 2018; 128: 171-7.

8. Zampieri FG, Ranzani OT, Sabatoski, et al. An increase in mean platelet volume after admission is associated with higher mortality in critically ill patients. Ann Intens Care 2014; 4: 20.
9. Ghosh TK, Khan N, Malik A. Platelet auto-antibod-ies in septicaemic patients. Indian J Pathol Microbiol 1999; 42: 31-5.

10. Greinacher A, Selleng K. Thrombocytopenia in the intensive care unit patient. Hematology Am Soc Hematol Educ Program Book 2010; $1: 135-43$

11. Nelson RB, Kehl D. Electronically determined platelet indices in thrombocytopenic patients. Cancer. 1981; 48.4: 954-6.

12.Zhang Z, Xu X, Ni H, Deng H. Platelet indices are novel predictors of hospital mortality in intensive care unit patients. J Crit Care 2014; 29: 885. e1-6.

13.Zhang S, Cui YL, Diao MY, Chen DC, Lin ZF. Use of platelet indices for determining illness severity and predicting prognosis in critically ill patients. Chinese Med J 2015; 128.15: 2012.

14. Becchi C, Al Malyan M, Fabbri LP, Marsili M, Boddi V, Boncinelli S. Mean platelet volume trend in sepsis: is it a useful parameter? Minerva Anestesiol 2006; 72.9: 749-56.

15. Han L, Liu X, Li H, et al. Blood coagulation parameters and platelet indices: Changes in normal and preeclamptic pregnancies and predictive values for preeclampsia. PLoS One 2014; 9: e114488.

16. Ghoshal K, Bhattacharyya M. Overview of platelet physiology: Its hemostatic and nonhemostatic role in disease pathogenesis. Scientific World Journal 2014; 781857.

17. Samuel D, Bhat AN, Prabhu VM. Platelet indices as predictive markers of prognosis in critically ill patients: a prospective study. Indian J Crit Care Med 2020; 24: 817-22.

18. Sezgi C, Taylan M, Kaya H, et al. Alterations in platelet count and mean platelet volume as predictors of patient outcome in the respiratory intensive care unit. Clin Respir J 2015; 9: 403-8. 